\title{
Genetic counseling after implementation of statewide cystic fibrosis newborn screening: Two years' experience in one medical center
}

\author{
Patricia G. Wheeler, $M D^{1}$, Rosemarie Smith, $M D^{1}$, Henry Dorkin, $M D^{2}$, Richard B. Parad, $M D, M P H^{3}$,
} Anne Marie Comeau, $P h D^{3}$, and Diana W. Bianchi, $M D^{1}$

\begin{abstract}
Purpose: To study the follow-up of genetic counseling performed in families with a newborn detected with one cystic fibrosis (CF) mutation in a statewide newborn screening pilot program. Methods: Newborns in Massachusetts with an elevated trypsinogen level on newborn screen who are found to have one mutation for CF on a selected mutation assay undergo sweat testing for CF, and their families receive genetic counseling. The genetic counseling focuses on carrier risk for the parents of the newborn and offers carrier testing. We studied the yield of genetic counseling and the resulting genetic testing performed on the families of infants found to be CF carriers who underwent sweat testing in a single institution. Results: Of 102 newborns evaluated with a single CF mutation, 2 (twins) had sweat test results consistent with CF. A total of 101 families were counseled, and 95 were offered DNA-based CF carrier testing. Eighty-two percent of all parents chose to have CF carrier testing, and in five couples, both members were carriers. One of these couples (whose newborn was only a carrier) had an older child who was unexpectedly found to have CF. Conclusions: Sweat testing of newborns at increased risk for CF in conjunction with genetic counseling for their parents allows identification of infants with CF, finds couples at high risk for having a child with CF, identifies previously undiagnosed siblings with CF, and allows for potential identification of CF carriers in the extended family. Genet Med 2001:3(6):411-415.
\end{abstract}

Key Words: cystic fibrosis, newborn screening, genetic counseling

Newborn screening for cystic fibrosis (CF) has gained increasing popularity in the past decade under the premise that diagnosis of CF in early infancy will allow for aggressive nutritional management and possible long-term reduction in the severity of lung disease. ${ }^{1-3}$ Initial studies appear to confirm a positive impact on nutrition while long-term effects on lung disease are still unclear. ${ }^{4-6}$ From a genetic perspective, diagnosing CF (an autosomal recessive disease) in an infant means that the parents are also diagnosed as obligate carriers of a $\mathrm{CF}$ mutation. In addition, some CF newborn screening protocols may detect infants who are only CF carriers, and thus at least one parent must be an obligate carrier.

On February 1, 1999, the state of Massachusetts added a pilot program for CF screening to its established newborn screening panel. The expanded statewide CF screening uses a two-tiered algorithm (IRT/DNA) modeled after the Wisconsin program $^{3}$ and modified to include DNA testing for multiple

\footnotetext{
From the ${ }^{1}$ Division of Genetics, ${ }^{2}$ Division of Pulmonology, Department of Pediatrics, Tufts University School of Medicine, Floating Hospital for Children at New England Medical Center, Boston, Massachusetts; and ${ }^{3}$ New England Newborn Screening Program, University of Massachusetts Medical School, Jamaica Plain, Massachusetts.

Patricia G. Wheeler, MD, Division of Genetics, Box 394, New England Medical Center, 750 Washington Street, Boston, MA 02111.

Received: July 23, 2001.
}

Accepted: September 6, 2001 cystic fibrosis transmembrane conductance regulator (CFTR) mutations. The general outlines of the algorithm have been previously presented. ${ }^{7,8}$ The infants in the present study all had elevated IRT levels (daily highest $10^{\text {th }} \%$ IRT levels through the first 8 months, then changed to highest $5 \%$ for the remainder of study period), and a single CFTR mutation detected from the DNA screening panel (Table 1). The protocol directs these infants to undergo definitive testing for $\mathrm{CF}$ by performing pilocarpine iontophoresis (sweat test) and recommends that the infant's family complete a formal genetic counseling session. This study summarizes the 2-year genetic counseling experience of one of five CF centers in Massachusetts that performs sweat testing and follow-up genetic counseling.

\section{METHODS}

In the first 2 years of this program, we evaluated 102 infants who were referred to our academic center after a newborn screen detected a single CFTR mutation because the presence of a second CFTR mutation not included in the screening panel could not be excluded. The Massachusetts CF newborn screening protocol states these infants should have a sweat chloride concentration determined (preferably at a CF Foundation Certified CF Center) and that families of infants determined by the sweat result to be carriers be offered genetic counseling. During the clinical genetics portion of the visit, 
Table 1

CFTR mutation panel used in the Massachusetts Cystic Fibrosis Newborn Screening Pilot Study

\begin{tabular}{lcr}
\hline deltaF508 & deltaI507 & R117H \\
$621+1 \mathrm{G}$ to T & R334W & R347P \\
A455E & 1717-1GtoA & G542X \\
S549N & G551D & R553X \\
R560T & N1303K & W1282X
\end{tabular}

$3849+10 \mathrm{~kb} \mathrm{C}$ to $\mathrm{T}$

${ }^{*}$ A559T, G85E, 2307insA, R1162X, S1255X, 1078delT, 2789+5G>A, 3120G $>$ A, 3659delC, $711+1 \mathrm{G}>\mathrm{T}, 405+3 \mathrm{~A}>\mathrm{C}, \mathrm{G} 480 \mathrm{C}$

${ }^{*}$ Mutations were added after 20 months, thus including infants screened in the last 4 months of the study period.

pregnancy, delivery, and medical history was obtained for each child. A family history was also obtained, including the ethnic background of the parents. At our center, the parents received genetic counseling before receiving the results of the sweat chloride test in the infants. The basic reasoning behind newborn screening and the reason CF testing was added to the newborn screen in Massachusetts was explained. In addition, the common medical problems associated with CF were described. Finally, the inheritance of CF was discussed primarily in the context of assuming the infant was likely to be only a carrier. Included in the discussion was the fact that one parent was an obligate carrier and that the risk for the other parent to be a carrier was estimated to be 1 in 25 for individuals of European or Ashkenazi Jewish descent. The reasons discussed for parental CF carrier testing included the risk that both parents could be CF carriers and, if only one parent was a carrier, that his or her siblings have a $50 \%$ chance of also being CF carriers. Parent carrier testing for CF by cheek brush sampling was described and performed at the end of the visit if one or both of the parents desired. The testing was either a 70 or an 87 CFTR mutation assay (the company doing the testing expanded the mutation panel mid-way through the first year). The newborn screening program did not cover the cost of carrier testing in the parents, but to date, the parental health insurance companies have covered the testing in the majority of cases. This coverage is primarily because, with a family history of a CF carrier (i.e., the infant), CF carrier testing was considered a diagnostic test and not a screening test in the at-risk parents. After the sweat test and genetic counseling visit, the family was notified of the child's sweat chloride results within 24 hours and all couples received a letter detailing the information discussed during the counseling session. The individuals who decided to have CF carrier testing were initially called, and then received a confirmatory letter, with their results. In addition, the carrier parent(s) received more in depth counseling regarding carrier risk in his or her extended family members, and we offered assistance in coordinating CF carrier testing if extended family members were interested. Several siblings of carrier parents have in fact contacted us to discuss carrier testing.

\section{RESULTS}

In the first 2 years of the newborn screening pilot study for $\mathrm{CF}$, our Center saw 102 infants who had a single CFTR mutation detected on the Massachusetts CF newborn screen for confirmatory sweat test and counseling. Of these infants, only two (twin boys, zygosity unknown) had sweat test results consistent with a diagnosis of cystic fibrosis (twin A's results were chlorides of $60 \mathrm{mEq} / \mathrm{L}$ and $63 \mathrm{mEq} / \mathrm{L}$ and twin B's results were chlorides of $58 \mathrm{mEq} / \mathrm{L}$ and $58 \mathrm{mEq} / \mathrm{L}$ ). Both children had a single deltaF508 mutation detected by the newborn screen. CFTR mutation testing for 70 mutations was done on their parents, and their father had a deltaF508 mutation, but no mutation has been identified in their mother to date.

Of the 101 families who were seen in the first 2 years of this pilot, four couples had had CF testing performed before or during the pregnancy. One couple had prior testing due to a family history of CF. Carrier testing for CF was offered to the other three couples as a part of antenatal screening per their obstetrician's protocol. Two of the at-risk children were not in the custody of their biological parents at the time of sweat

\section{5 couples offered testing}

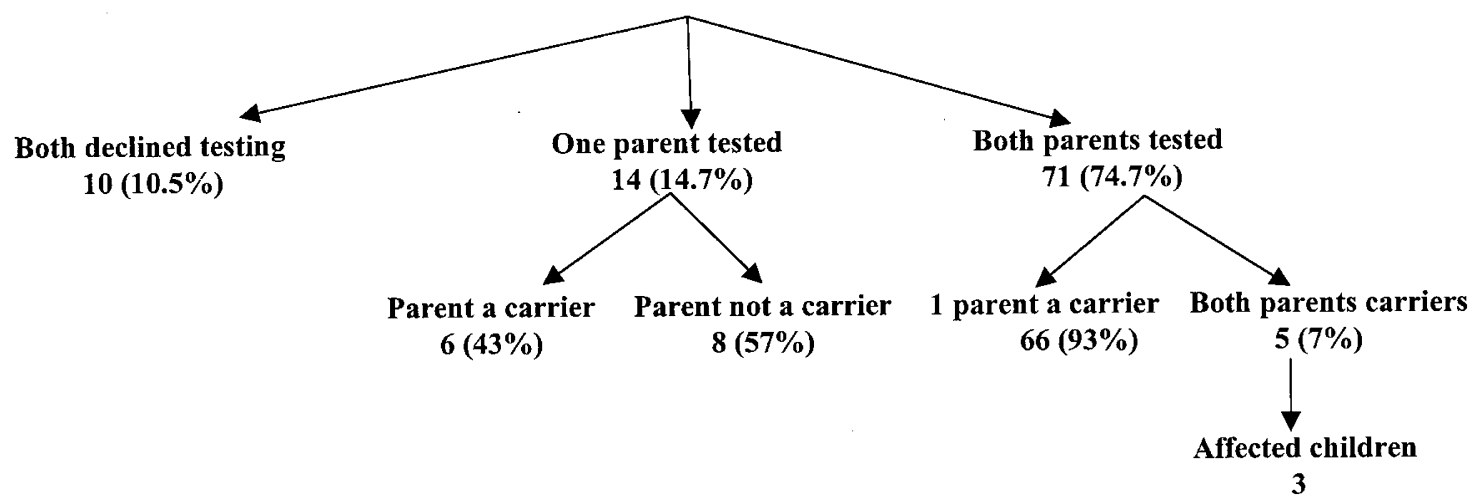

Fig. 1 Results of genetic counseling for cystic fibrosis carrier status. 
chloride testing. Ten percent (10 of 95) of the remaining couples declined CF carrier testing (Fig. 1). Reasons given included no further children were planned, and the anxiety of waiting for the sweat test results made it impossible for them to consider testing on themselves. In 14.7\% (14 of 95) of couples, only the mother was tested, either because the father was not available, he did not wish testing, or he did not have insurance coverage. In the couples in which only the mother was tested, 8 of 14 mothers were negative for a CF mutation; therefore, the father was considered an obligate carrier. The other six mothers were positive for the same mutation seen in the infant. To date, none of their partners have been tested for their CF carrier status, even though this testing was recommended.

Seventy-five percent (71 of 95) of couples decided to have carrier testing. In 66 of the couples, only one member of the couple was found to be a carrier, and in all cases, the carrier parent had the same mutation as the baby. In five couples, both members were found to be CF carriers. If one assumes a 1/30 carrier rate, a rough estimate of the number of families with 2 carriers would be 2.4 . The $95 \%$ confidence intervals for the estimate of the number of families with 2 carriers is 0.24 to 6.0. Therefore, finding five couples in which both were carriers is consistent with what would be expected in this population. Two of the couples had another child who was initially reported to be healthy and well, but due to the parental status both children had sweat testing done. The testing showed that one of the children (a 26-month-old) had CF, a diagnosis that had not previously been considered, although subsequent review of her medical history revealed her to have abnormal stools. All five couples in which both members were CF carriers were brought back to clinic and re-counseled regarding the $25 \%$ risk with each pregnancy of having a child with CF. Options for future pregnancies, including prenatal and preimplantation diagnosis, were discussed with each couple.

\section{DISCUSSION}

The intent of the newborn screening program in Massachusetts is to diagnose infants with CF as early in life as possible. A side effect of this program is that some infants, and thus at least one of their parents, are diagnosed as carriers for CF. This diagnosis was not the original intent of the screening program but was believed to be a reasonable trade-off to ensure as few false-negative results as possible. This finding makes genetic counseling of the family more complicated, since the majority of couples do not realize that the newborn screen can also diagnose their child as being a carrier for a CF mutation.

More of the parents seen in our study (82\%) decided to have $\mathrm{CF}$ carrier testing than has been previously reported in similar circumstances $(\sim 50 \%) .{ }^{9}$ Possible factors that might explain differences in this yield include timing of the counseling (whether it was tied directly to the sweat test or offered at a return visit), whether the counseling was performed before or after the sweat test, the ease in availability of genetic testing to the family (on-site cheekbrush in our case), and whether counseling or testing had to be preapproved by insurers. In the study by Mischler et al., ${ }^{9} \mathrm{CF}$ carrier testing occurred at a second visit after the initial genetic counseling. Attrition is a likely sideeffect of requiring a second visit for testing. In our institute, counseling was done before giving sweat test results primarily for the convenience of the family, because our laboratory typically would take more than an hour to obtain results. We believed, given the very low chance for the infant to have CF, that we could primarily discuss carrier risks and carrier testing for the parents. The description of CF was brief and more for the purpose of explaining why carrier testing was being offered to the parents rather then preparing the family for a possible diagnosis of CF. The reasons couples gave in our study for having carrier screening done included concern over whether both could be CF carriers, and if only one was a carrier, the desire to know if other family members were also at risk to be carriers. At our institute, an MD clinical geneticist provided all of the genetic counseling, primarily because that was who was available. The counseling could also have been done by a genetic counselor. If CF newborn screening as described here becomes more prevalent in the United States, there will be a great need for individuals who can explain the testing and the carrier risks. We believe that such explanations are best given by individuals trained in genetic counseling, whether they be clinical geneticists or genetic counselors.

Of interest in our 101 families were those in which both parents were found to be CF carriers either through DNA testing or by their newborn having an abnormal sweat chloride concentration. Of these five families, only one presented with affected children (the twins). Another presented with a newborn who was only a CF carrier, but this finding led to an older sibling unexpectedly being found to have CF. Fortunately, the other three families did not have any affected children, but these couples were all considering having further children. Without the newborn screening for CF, these couples would not have known of their risk to have a child with CF. The $25 \%$ risk of having a child with CF has caused them to seriously consider whether or not to have more children, although to date none of these couples have made a definitive decision.

The advantages of performing sweat tests in conjunction with genetic counseling to parents include identifying the minority of infants with elevated trypsinogen levels and one detected CFTR mutation who are affected with CF, finding couples at high risk for having a subsequent affected child, identifying a previously undiagnosed sibling with CF, and potential identification of CF carriers in the extended family. The disadvantage of this IRT/DNA screening algorithm is identification of some infants who are only CF carriers (and, thus, at least one parent is an obligatory carrier) whether or not these individuals wish (or will wish) to know their carrier status.

One concern with newborn screening programs that use DNA testing as part of the screening process is that many infants who present with a single mutation on initial screening have been found to be only carriers. The American Society of Human Genetics, the American College of Medical Genetics, and the American Academy of Pediatrics (AAP) have recommended that testing children for carrier status for autosomal 
recessive conditions or presymptomatic testing for late-onset autosomal dominant conditions be delayed until a child is of sufficient maturity to understand the testing and agree to have the test done. ${ }^{10,11}$ Obviously, a newborn's consent cannot be obtained, and in the case of newborn screening, the AAP recommends that "newborn screening tests be introduced in a carefully designed manner that facilitates evaluation of the risks and benefits of screening, including the efficacy of follow-up and treatment protocols." ${ }^{10}$ The main concern from an ethical standpoint is that we are preventing an individual's freedom of choice with regard to diagnosis of his or her carrier status. As more and more genetic conditions are being mapped, this dilemma will come up more frequently and needs to be taken into consideration as part of the cost benefit equation when newborn screening is being planned.

CF carrier testing in the general population has been somewhat controversial, even though a 1999 National Institutes of Health (NIH) consensus development conference statement on genetic testing for cystic fibrosis recommended that CF testing should be offered to adults with a positive family history of $\mathrm{CF}$, to partners of people with CF, to couples currently planning a pregnancy, and to couples seeking prenatal care. ${ }^{12}$ The American College of Medical Genetics (ACMG) and the American College of Obstetrics and Gynecology are in the process of determining exactly how such carrier testing should be implemented. ${ }^{13}$ A recent statement from the ACMG recommends offering CF carrier testing to all couples of non-Jewish Caucasian descent and of Ashkenazi Jewish descent. CF carrier testing should also be discussed with individuals of other racial and ethnic groups with the caveat that $\mathrm{CF}$ is much rarer in these populations and detection rates of CF mutations is also low. ${ }^{14}$ Even within the Caucasian population, a 25 CFTR mutation panel will only ascertain $80 \%$ of individuals of Northern European ancestry with a CFTR mutation. ${ }^{14}$ The ascertainment level is lower in other ethnic groups, particularly Hispanics and African Americans. An individual of Northern European descent has an $\sim 1$ in 25 risk to be a CF carrier prior to any testing. If this individual has a negative result after carrier testing for 25 CFTR mutations, then his or her risk to be a CF carrier decreases to 1 in 140, which means there is still a small risk that he or she may be a carrier. ${ }^{14}$ One of the most difficult aspects of genetic counseling is ensuring that individuals understand that this testing only reduces their risk to be a carrier. It does not eliminate the risk. Thus, we believe that it will be important to have adequate genetic counseling resources, including explanatory literature and, if necessary, a genetic counselor or clinical geneticist, available to explain to individuals and couples the results of their testing if nationwide CF carrier testing is instigated.

How does national CF carrier screening impact on newborn screening for CF? While it would be preferable to detect all couples at risk to have a child with CF before a pregnancy or delivery, this is unlikely to happen due to some individuals' reluctance to be tested, the limitations of the testing as described above, and the fact that a significant proportion of the population does not access any prenatal care, let alone special- ized services. The goal of newborn screening for CF is to identify affected children as early in life as possible; thus, relying only on preconceptual or prenatal testing of parents is not sufficient. Ideally, newborn screening for CF would avoid detection of infants who are only CF carriers, which would obviate the ethical dilemma of lack of informed consent from the individual being tested. Such testing is not yet available, but hopefully, as we learn more about early indicators of CF disease, screening algorithms can be improved to lower the number of babies for whom DNA testing will be prompted. Alternatively, the ability to economically and rapidly sequence entire genes will help to distinguish with near 100\% accuracy individuals who are likely to be affected with CF and those who are only carriers based just on the initial blood sample for the newborn screen.

In summary, we have presented our experience with the genetic counseling performed at one academic center that evaluates infants with an abnormal IRT/DNA cystic fibrosis newborn screen, who have a single CFTR mutation detected, and are directed to undergo both sweat testing and genetic counseling. As a result of this protocol, three additional children with CF were detected, five couples found out that they had a $25 \%$ risk of having an affected child, and extended family members were made aware of their risk to be CF carriers. The long-term implications of diagnosing carrier status for an autosomal recessive disease in a newborn requires further public policy discussion.

\section{Acknowledgments}

The authors thank the Massachusetts Cystic Fibrosis Work Group, without whom this work could not have been done: Robert Gerstle, Baystate Medical Center; Allan Lapey, Massachusetts General Hospital; Henry Dorkin, New England Medical Center; David Waltz, The Children's Hospital; and Robert Zwerdling, University of Massachusetts Medical School.

\section{References}

1. Ranieri E, Ryall RG, Morris CP, Nelson PV, Carey WF, Pollard AC, Robertson EF. Neonatal screening strategy for cystic fibrosis using immunoreactive trypsinogen and direct gene analysis. BMJ 1991;302:1237-1240.

2. Ferec C, Velingue C, Parent P, Morin JF, Codet JP, Rault G, Dagorne M, Lemoigne A, Journel H, Roussey M, Le Marec B, Catheline M, Audrezet MP, Mercier B. Neonatal screening for cystic fibrosis: result of a pilot study using both immunoreactive trypsinogen and cystic fibrosis gene mutation analyses. Hum Genet 1995;96:542548.

3. Gregg RG, Simantel A, Farrell PM, Koscik R, Kosorok MR, Laxova A, Laessig R, Hoffman G, Hassemer D, Mischler EH, Splaingard M. Newborn screening for cystic fibrosis in Wisconsin: comparison of biochemical and molecular methods. Pediatrics 1997;1997:99:819-824.

4. Chatfield S, Owen G, Ryley HC, Williams J, Alfaham M, Goodchild MC, Weller P. Neonatal screening for cystic fibrosis in Wales and the West Midlands: clinical assessment after five years of screening. Arch Dis Child 1991;66:29-33.

5. Waters DL, Wilcken B, Irwig L, Van Asperen P, Mellis C, Simpson JM, Brown J, Gaskin KJ. Clinical outcomes of newborn screening for cystic fibrosis. Arch Dis Child Fetal Neonatal Ed 1999;80:F1-F7.

6. Farrell PM, Kosorok MR, Laxova A, Shen G, Koscik RE, Bruns WT, Splaingard M, Mischler EH. Nutritional benefits of neonatal screening for cystic fibrosis. $\mathrm{N} \mathrm{Engl}$ J Med 1997;33:963-969.

7. Cono J, Qualls N, Khoury M, Hannon W. Newborn screening for cystic fibrosis: a paradigm for public health genetics policy development. Proceedings of a 1997 workshop. MMWR Morb Mortal Wkly Rep 1997;46:1-24. 
8. Parad RB, Comeau AM, Eaton RB, Dorkin H, Dovey M, Gerstle R, Lapey A, Zwerdling R. Massachusetts pilot program for cystic fibrosis newborn screening suggests a difference between observed and predicted incidence, carrier frequency and deltaF508 allele frequency. Pediatr Pulmonol 1999;S19:336.

9. Mischler EH, Wilfond BS, Fost N, Laxova A, Reiser C, Sauer CM, Makholm LM, Shen G, Feenan L, McCarthy C, Farrell PM. Cystic fibrosis newborn screening: impact on reproductive behavior and implications for genetic counseling. Pediatrics 1998;102:44-52.

10. American Academy of Pediatrics, Committee on Bioethics. Ethical issues with genetic testing in pediatrics. Pediatrics 2001;107:1451-1455.

11. ASHG/ACMG Policy Statement. Points to consider: ethical, legal, and psychosocial implications of genetic testing in children and adolescents. Am J Hum Genet 1995; 57:1233-1241.
12. National Institutes of Health Consensus Development Conference Statement on Genetic Testing for Cystic Fibrosis. Genetic testing for cystic fibrosis. Arch Intern Med 1999;159:1529-1539.

13. Haddow JE, Bradley LA, Palomaki GE, Doherty RA, Bernhardt BA, Brock DJH, Cheuvront B, Cunningham GC, Donnenfeld AE, Erickson Jl, Erlich HA, Ferrie RM, FitzSimmons SC, Greene MF, Grody WW, Haddow PK, Harris H, Holmes LB, Howell RR, Katz M, Klinger KW, Kloza EM, LeFevre ML, Little S, Loeben G, McGovern M, Pyeritz RE, Rowley PT, Saiki RK, Short MP, Tabone J, Wald NJ, Wilker NL, Witt DR. Issues in implementing prenatal screening for cystic fibrosis: results of a working conference. Genet Med 1999;1:129-135.

14. Grody WW, Cuttting GR, Klinger KW, Richards CS, Watson MS, Desnick RJ. Laboratory standards and guidelines for population-based cystic fibrosis carrier screening. Genet Med 2001;3:149-154. 